\title{
The Failure of Economic Theory. Lessons from Chaos Theory
}

\author{
Marisa Faggini, Anna Parziale \\ Dipartimento di Scienze Economiche e Statistiche, University of Salerno, Salerno, Italy \\ Email: \{mfaggini, aparziale\}@unisa.it
}

Received September 6, 2011; revised November 2, 2011; accepted November 26, 2011

\begin{abstract}
The crisis that was being shaken the world economy should push economists to wonder about the approach used to analyse economic phenomena. The motivations that have generated it, describing a whole of interdependencies, interacttions, are clear and convincing. But a question remains: if the situation is so clear a posterior why economists have not been able to foresee it? What is happening to economic science if it is not able to recognize an economic crisis before it "steps on it"? How is it possible that the economic science was caught off guard yet again? Besides, what is the implication for the status of economics as a science if it is not able to successfully deal with real economic problems? The aim of the paper is to show the weakness of traditional economic theory and what improvements in terms of description and foresight could be obtained applying chaos theory to the study of economic phenomena.
\end{abstract}

Keywords: Economic Mainstream; Chaos Theory; Nonlinear Systems

\section{Introduction}

In his work of 1992 Allais said: “...the essential condition of any science is the existence of regularities which can be analysed and forecast. This is the case of celestial mechanics but it is true for many economic phenomena whose analysis displays the existence of regularities which are similar to those found in the physical sciences. This consideration is the basis of why economics is a science, and why this science can rest on the same general principles and methods of classical thermodynamics and in general as Physics" [1].

This sentence resumes the opinion of almost of economists have long been trying to build economic models that apply mathematical laws of hard sciences, in particular, physics. The aim was to create a real mathematical economics on those models.

Some of important exponents of neoclassic economics explicitly declared their intentions of transferring to economics the concepts and the methods used in physics [2].

Jevons [3] said that "Economics, if it is to be a science at all, must be a mathematical science [...] mechanics of utility and self-interest." Walras maintained "that economics, like astronomy and mechanics is both an empirical and a rational science." Its explanation of the existence of an "auctioneer," whose only purpose was to generate equilibrium prices evokes Maxwell's imaginary demon. Fisher, developed a mechanical analogy between economics and physics, claiming force and distance to be analogous to price and number of goods, respectively.

Later von Neumann [4], Samuelson [5]), and Georgescu-Roegen [6] proposed a description of economic systems following the classical thermodynamics ${ }^{1}$. Samuelson acknowledges that the relationships between pressure and volume in a thermodynamic system bear a striking similarity in terms of differentials to price and volume in an economic system. Economics is formally identical to thermodynamics because they are both problems of static constrained optimisation.

Various reasons supported this research of similarities and/or analogies. On one hand, physics was a science that they were all well acquainted with ${ }^{2}$; on the other hand it was very highly considered for the significant successes it had achieved and by its extensive use of mathematics.

In particular this last aspect constituted the primary element to give a discipline such as economics, whose mathematical foundations were rather vague at the time, a more scientific character.

The possibility that there should be similarities of structure or interpretation in the mathematical modelling of economic and physical systems has been an important

\footnotetext{
${ }^{1}$ For similarity between economics and physics see [7].

${ }^{2}$ Jevons graduated in chemistry at University College London, where, later, he became a professor of political economics, having been a student of the mathematician George Boole; Pareto graduated in civil engineering from Turin Polytechnic; Fisher had been a student, at Yale University, of Josiah Williard Gibbs, an eminent figure in mathematical physics and one of the fathers of theoretical thermodynamics.
} 
focus in the economic speculation that produced the neoclassical theory based on the following assumptions.

Firstly, the representative agent who is a scale model of the whole society with extraordinary capacities, particularly concerning the area of information processing and computation. Secondly, it proposes equilibrium as a natural end of economic systems. Lastly, linear models or, at least, the linearization of models have been traditionally preferred by economists. So described, Economics is largely a matter of formalized thin fiction that has little to do with the wonderful richness of the facts of the real world. The criticism ${ }^{3}$ often voiced was that "these assumptions are frequently made for the convenience of mathematical manipulation, not for reasons of similarity to concrete reality" [8].

Now because "economics is a science of thinking in terms of models joined to the art of choosing models that are relevant to the contemporary world, despite the undisputable success of those models their limitations are nowadays hard to ignore.

Since the 1970s the irruption of the nonlinearity led to a profound transformation of numerous scientific and technical fields and Economics does not escape this revolution. Chaos theory, in particular has improved the probabilities of achieving good results in the modelling of phenomena and their empirical analysis.

In economics chaos theory has attracted particular attention because of its ability to produce sequences whose characteristics resemble the fluctuations observed in the market place. Most economic variables whether microlevel, such as prices and quantities, or at the macro-level, such as consumption, investment and employment, oscillate and these oscillations too often were interpreted simply as exogenous shocks.

However the goal of this paper is to redirect the attention of economists and policy-makers towards an alternative approach that significant results have reached in other scientific fields and that could contribute to ameliorate the economic analysis. We did not claim that this alternative approach would have provided answers, or that chaotic models could have predicted the crisis. Given the complexity of economy, "we believed that a healthy profession would be working on a variety of models and that it would be engaged in a vigorous debate about what the various models were telling us and which models were better" [10]. Therefore starting from the descriptions about the basic assumptions made in economic theory the aim of this paper is to highlight the major contribute of chaos theory in improving the description, analysis, and control of economic processes and the re-

\footnotetext{
${ }^{3}$ The idea is to focus on one or two causal or conditioning factors, exclude everything else, and hope to understand how just these aspects of reality work and interact...modern mainstream economics consists of little else but examples of this process” [9, p. 43].
}

sults reached until now by economists that have applied this theory to economic analysis.

The paper is structured as follows. In the Section 2 we will analyse the methodology used to build a model describing economic phenomena. In the Section 3 the improvements in the economic analysis reached application of chaos theory will be displayed. In the Section 4 the question of presence of chaos in economic time series are described. Some conclusions are presented in Section 5.

\section{Economic Mainstream}

The economics profession spends much of its time on what was called a Walrasian general equilibrium model, based on the assumptions, which are more analytically tractable and interesting for a few limited phenomena.

The large majority of economic models share a common element: they depart, in one way or another, from the benchmark of competitive markets with fully rational agents (consumer and firms), representative of all members of some class of agents with identical preferences and endowments.

The market is a locus of impersonal exchange activities, where agents buy and sell products with defined characteristics, at prices that-according to standard economic theory - reflect supply and demand induced equilibria.

Economic theory accords these prices the role of principal communication media between agents, who use the information prices convey to drive the actions they take in the economy. Relationships between agents do not count for much in "the market". What matters is how each agent separately values each action in "the market", values that "the market" then aggregates into prices. Individuals are the basic unit of analysis. Economic phenomena are decomposed into sequences of individual actions set aside culture, psychology, class, group dynamoics, or other variables that suggest the heterogeneity of human behaviour. Economic actors are treated as equivalent or the differences among them are presented as attributes of individuals. The regularities not the differences are considered. This is what required from the assumption of representative agent, a scale model of the whole society with extraordinary capacities, particularly concerning her capability of information processing and computation. But that is not the only restrictions to economic analysis. The second one is the study of economic systems in a state of equilibrium. The last one is the use of linear models or, at least, its linearization in the neighbourhood of equilibrium.

The reductionist approach, applied by traditional economic theory, often overlooks the dependencies or interconnections among elements and their influence upon macroeconomic behaviour. Its focus is not to study the unfolding of the patterns its agents create, but rather to simplify its questions in order to simplify and seek closed 
analytical solutions.

\subsection{The Representative Agent}

In order to abstract from heterogeneity, which allows the application of rigorous calculus and to economics to gain deep insights embedded in a formal elegant framework, the explanation of human behaviour is brought back that of representative agent: an agent that acts with rationality when making choices and her choices are aimed to optimization of her utility or profit. What is taken as "rational" is of chief importance because rationality is used either to decide which course of action would be the best to take, or to predict which course of action actually will be taken, to have time and ability to weigh every choice against every other choice and finally to be aware of all possible choices. Further, individual preferences are taken to be given a priori, rather than constructed and revised through ongoing social processes: they are primitive, consistent, and immutable.

In a more formal sense the economic agents are said to have transitive and consistent preferences and seek to maximize the utility that they derive from those preferences, subject to various constraints. They operate according to imperative choice: given a set of alternatives, choose the best.

This process of choice postulates utility values associated with possible states of the world perfectly foreseen in which situations with higher utilities are preferred to those with lower ones. Choices among competing goals are handled by indifference curves-generally postulated to be smoothing (twice differentiable) — that specify substitutability among goals.

The consumer maximizes his utility subject to the budget constraint and solve out the maximization problem in order to get some form of demand function for the consumer.

The solution of this optimization problem is an individual demand curve used as the exact specification of the aggregate deduced just summing up the behavior of agents that compose a market or an economy.

So the result of decision problem of the representative economic unit is the results of aggregate quantities. There are not significant differences between micro end macro levels: the dynamics of this latter is just the summation of dynamics of the former. The behaviour of an economic group is adequately represented by that of a group, each of whose members have the identical characteristics of the average of the group.

Consider the efficient market hypothesis, which has ruled the root for some years in finance. Its originator was Louis Bachelier, who developed the notion of Brownian motion at the turn of the twentieth century. His argument that stock prices should follow this sort of stochastic process, after years of being ignored, was acclaimed by economists both for analytic and ideological reasons. Then Henri Poincaré [11], French mathematician, observed that it would not be sensible to take this model as a basis for analyzing financial markets. Individuals who are closed to each other, as they are in a market, do not take independent decisions - they watch each other and "herd". Thus Poincaré clearly envisaged one of the most prevalent features of financial markets long before modern economists took this theme up to explain "excess volatility" [12].

Markowitz [13] developed his theory of optimal portfolio using the assumption that the changes in returns on assets had a Gaussian distribution. Despite the empirical evidence and the pleas of Mandelbrot and others, this assumption prevailed, since one could apply the central limit theorem to it, unlike the family of Levy stable distributions favoured by Mandelbrot. The same thing applies to the development of Black-Scholes [14] option pricing. This again relies on the refutable and often-refuted assumption that the price of an asset follows a lognormal process [12].

Some doubts come up: does the real economy work in this way? Is this approach adequate to describe a world in which agents use inductive rules of thumb to make decisions, they have incomplete information, they are subject to errors and biases, they learn to adapt over time, they are heterogeneous, they interact one another, in a few words are not rational in a conventional sense?

The reality provides a wealth of evidence showing that the rationality in question has little or nothing to do with how people behave.

\subsection{Equilibrium Models}

Strictly connected with representative agent is the equilibrium notion meant to provide a credible explanation of observed economic phenomena and a guide to economic policy making.

"A characteristic feature that distinguishes economics from other scientific fields is that, for us, the equations of equilibrium constitute the center of our discipline. Other sciences, such as physics or even ecology, put comparatively more emphasis on the determination of dynamic laws of change" [15]. As said above Economics seeks to describe phenomena in terms of solutions to constrained optimization problems.

The consumers determine how much they wish to demand of some good as function of its price. Similarly the producers determine using the same maximization process the amount of that good that desire to supply.

Denoted with $D(p)$ the demand curve and with $S(p)$ the supply curve if a price $p$ the amount of the good demanded $\mathrm{D}(\mathrm{p})$ will be compatible with amount supplied $\mathrm{S}(\mathrm{p})$ the market is in equilibrium. The agents' trades are compatible and we say "a unique and stale equilibrium exists". 
The normal economic order is a static equilibrium state plus small random noise.

To have a unique and stable equilibrium it needed to impose to the model four basic constraints.

First, increasing returns to scale are not allowed the hypothesis is of decreasing returns. Second, information diffusion and reaction does not occur among the agents: they are rational; they have all information about their actions. Third, the dimension of commodity space is fixed where no product innovations are allowed. Fourth resource limits and market extent are ignored.

The equilibrium in a general equilibrium model is not necessarily either unique or stable.

Colander [16] identifies three distinguishing characteristics of the post-Walrasian perspective. First, the equations necessary to describe the economy have multiple equilibria and complex dynamics. Second, individuals act on the basis of local, bounded rationality, since global rationality is beyond anyone's information processing capabilities. Finally, institutions and non-price coordinating mechanisms are the source of systemic stability in a market economy. It is widely believed among economists that equilibrium economics provides a consistent framework in economics, which is capable in explaining almost everything from demand and supply in micro, money and unemployment in macro, corporate finance and asset pricing in finance, even firms and law in institutional economics.

\subsection{Linear Models}

For a long time scientific models of exact sciences were built starting from the consideration that causal mechanisms of natural phenomena were linear. The world of classical science has shown a great deal of interest in linear differential equations for a very simple reason: apart from some exceptions, these are the only equations of an order above the first that can be solved analytically. Linearity is intrinsically "elegant", because it is expressed in simple, concise formulae, and a linear model is aesthetically more "attractive" than a nonlinear one.

Following this tendency the economic science described the economic phenomena using linear equations and when irregular behaviour of some nonlinear relations are found, they are not appreciated because they are difficult and intractable to deal with. So they have been explained as stochastic or linearized.

Because it may be difficult in models to deal with many variables leading economists use numerical approximations or linearisation around a 'steady state' where in economics a steady state is a point $\mathrm{x}$ such that if is an equilibrium at time $t$, then it is also an equilibrium at time $(t+1)$. The simplicity of linearization and the success that it has at times enjoyed have imposed, so to say, the perspective from which scientists observed reality, encouraging scientific investigation to concentrate on linearity in its descriptions of dynamic processes.

To tackle the study of the dynamics of systems when the latter are in a condition that is close to stable equilibrium has been preferred because there the forces in play are small.

The idea is simply that, as the terms that were ignored by linearizing the equations were small, the difference between the solutions of the linearized equation and those of the nonlinear equation assumed "true", but unknown, ought to be small as well. However, this is not always the case. Many fundamental problems remain unsolved.

Conceptualizing, measuring, and modeling cause-effect linear relationships in economic systems is sometimes ineffective and inefficient. On the contrary, it is usually closer to reality to propose that relationships among the economic agents and variables are non-linear.

The nonlinearity implies the loss of the causality correlation between the perturbation and effect propagated in time, assumption that characterises many economic models.

Nonlinear dynamics tend to arise as the result of relaxing the assumptions underlying the competitive market general equilibrium approach.

Nonlinear dynamics are the fruit of increasing returns to scale, bounded rationality and heterogeneity of expectations. The reductionist approach, applied by traditional economic theory, overlooks these dependencies or interconnections among elements and their influence upon macroeconomic behaviour, so both deterministic and stochastic descriptions are used to define main features of economic dynamics [17].

\section{Chaos Theory in Economics}

The new perspective opened by chaos theory has spawned significant changes in mainstream economic theory improving the probabilities of achieving good results in the modelling of phenomena and their empirical analysis. The challenge that the macroeconomic theorist faces is whether she is capable of changing benchmark models in order to simultaneously make more realistic assumptions and as well attain more realistic results.

Chaos theory stimulates the search for a mechanism that generates the observed movements in real economic data and that minimizes the role of exogenous shocks. In this sense it could represent a shift in thinking about methods to study economic activity and in the explanation of economic phenomena such as fluctuations, instability, crisis, and depressions.

Economists began to look at the analysis of global dynamics in the late 1970s and the 1980s, with important work by Medio [18], Stutzer [19], Benhabib and Day [20], Day [21], Grandmont [22], and many others, some 
of them to be referred in following sections.

In 1980 the pioneering work by Benhabib and Day [20,21], has been important for making the economists aware of the potential usefulness of chaos theory and its tools for analyzing economic phenomena. Since this work there has been an enormous number of papers addressed to investigate the presence of chaotic dynamics in standard models. Benhabib and Nishimura [23] employ the Hopf bifurcation in their study of how the properties of an optimal growth model are affected by the discount rate. Benhabib and Day [20], Grandmont [22] and Boldrin and Montrucchio [24] derived chaotic business cycle models from utility and profit maximization principles within the general equilibrium paradigm of perfectly competitive markets and rational expectations.

Day [21] attracted considerable attention to the possibility of chaos in two quite familiar contexts: a classical growth model and a Solow growth model. Chaos has also been analyzed in the context of a multiplier acceleratortype model by Dana and Malagrange [25]. Deneckere and Pelikan [26] discuss some necessary conditions for chaos Hommes [27] showed how easy it is to produce chaos in Hicksian-type models with lags in investment and consumption. Bala et al. [28] located sufficient conditions for robust ergodic chaos to appear in growth models. Mitra [29] shows the existence of chaotic equilibrium growth paths within a model of endogenous growth with externalities.

Grandmont [30] is concerned with the effects of various government policies while Grandmont and Laroque [31] demonstrate the importance of the expectations formation mechanism for the stability of economy. Farmer [32] and Reichlin [33] both consider production economies and both make use of Hopf bifurcation which is often thought to be more robust than the flip bifurcation. In Farmer [32] chaos depends upon the government's debt policy. In Reichlin [33] it is shown that fiscal policy can cure chaos in the sense of suppressing chaos.

Chiarella [34] introduced a general nonlinear supply function into the traditional cobweb model under adaptive expectations, and showed that in its locally unstable region it contains a regime of period-doubling followed by a chaotic regime.

Puu [35] studied the nonlinear dynamics of two competing firms in a market in terms of Cournot's duopoly theory; by assuming iso-elastic demand and constant unit production costs this model shows persistent periodic and chaotic motions.

A common feature of the models described above is that nonlinear dynamics tend to arise as the result of relaxing the assumptions underlying the competitive market general equilibrium approach.

\subsection{Chaos Control in Economics}

The interests of economists in the chaos theory derive also from the fact that this theory could offer also a new perspective in system control strategies which has some particularly interesting insights for economic policies.

The current opinion among scientists was that chaotic motion in systems is neither predictable nor controllable because of the sensitive dependence on initial conditions. Small disturbances lead only to other chaotic motions and not to any stable and predictable alternative. Ott, Grebogi and Yorke [36] proposed an ingenious and versatile method for controlling chaos. The key achievement of their paper was to show that control of a chaotic system can be made by a very small, "tiny" correction of its parameters. This observation opened possibilities for changing behaviour of natural systems without interfereing with their inherent properties.

If the system is non-chaotic the effect of an input on the output is proportional to the latter. Vice versa when the system is chaotic, the relations between input and output are made exponential by the sensitivity to initial conditions. We can obtain a relatively large improvement in system performance by using small controls $[37,38]$. These considerations are particularly interesting in the applications of control of economic systems.

First, moving from given orbits to others on the attractor means choosing a different behaviour for economic systems, that is, different trade-offs in economic policy. This richness of possible behaviors (many aperiodic orbits) in chaotic systems may be exploited to enhance the performance of a dynamical system in a manner that would not be possible to have if the system's evolution is not chaotic.

Second, employment of an instrument of control in terms of resources in order to achieve a specific goal of economic policy will be lesser in magnitude when compared to the use of traditional control techniques.

Lastly, using control based on sensitivity to initial conditions could mean greater efficiency, especially in terms of needed resources to accomplish economic policy goals.

Therefore if the system is chaotic, limited resources do not reduce the possibility by policy-makers to reach predetermined goals of economic policies.

The government may be able to manipulate some policy parameters in order to shift the economic system from a position of chaos to a fixed point outcome and in this way fulfil its stabilization goal (if one accepts the idea that the government should be mainly concerned with eliminating or mitigating fluctuations). A problem with the manipulation of policy parameters is that the changes needed to leave instability or chaos to achieve a fixed point are often unrealistic [39].

The methods of controlling chaotic dynamics have been applied to economic models in works by Holyst [40], Holyst and Urbanovwicz [17], and Kaas [41]. Kopel [42] uses a simple model of evolutionary market dynamics 
showing how chaotic behaviour can be controlled by making small changes in a parameter that is accessible to the decision makers and how firms can improve their performance measures by use of the targeting method.

$\mathrm{Xu}$ et al. [43] introduced an approach to detect UPOs patterns from chaotic time series data from the Kaldor business cycle model. Kaas [41] proved that within a macroeconomic disequilibrium model stationary and simple adaptive policies are not capable of stabilizing efficient steady states and lead to periodic or irregular fluctuations for large sets of policy parameters. The application of control methods to chaotic dynamical systems shows that the government can, in principle, stabilize an unstable Walrasian equilibrium in a short time by varying income tax rates or government expenditures.

\section{Chaos Theory and Economic Time Series Analysis}

The relevance of addressing chaos in economic models and the potentiality offered by its control techniques is associated to detecting the presence of chaotic motion in economic data. From an empirical point of view it is difficult to distinguish between fluctuations provoked by random shocks and endogenous fluctuations determined by the nonlinear nature of the relation between economic aggregates.

If, hypothetically, it were possible to clearly separate stochastic and deterministic components of economic time series, this would be important from a policy point of view. While purely stochastic trajectories do not allow forecasting future outcomes, chaotic series are deterministic and thus, if one knows exactly which the initial state of the system is, then future outcomes are obtainable with full accuracy.

Nevertheless the existence of economic chaos is still an open issue [44-49]. Trends, noise, and time evolution caused by structural changes are the main difficulties in economic time-series analysis.

The main and more used tests for chaos applied either in macroeconomic and financial time series are: correlation dimension; Lyapunov exponent; and BDS test.

The correlation dimension, developed in physics by Grassberger and Procaccia [50], is based on measuring the dimension of a strange attractor. Its major advantage is the simplicity of calculating. However this analysis provides necessary but not sufficient conditions for testing the presence of chaos. In fact, designed for very large, clean data sets, it was found to be problematical when applied to short time series [51].

The Lyapunov exponent is generally regarded as necessary but not sufficient conditions for chaos. As for correlation dimension, the estimate of Lyapunov exponent requires a large number of observations. Since few economic series of such a large size are available, Lyapunov exponent estimates of economic data may not be so reliable.

One other of the most commonly applied tool is the BDS $^{4}$ test by Brock, Dechert, and Scheinkman [54]. It is not a test for chaos [55] but tests the much more restricttive null hypothesis that the series is independent and identically distributed. It is useful because it is a well defined, easy to apply test, and powerful against any type of structure in a series. It has been used most widely to examine a variety of economic and financial time series.

Although the literature on tests for chaos in economic time series is, by now, somehow voluminous, there are no uncontroversial results to state. The application of these tests to such data presents numerous problems. The first problem is that noise of economic time series may render any dimension calculation useless [46]; then, to obtain a reliable analysis, large data sets are required. Data quantity and data quality are crucial in applying them and the main obstacle in empirical economic analysis is short and noisy data sets.

Especially, testing on macroeconomic series are regarded with some suspicion; not only the gathered data is insufficient to perform tests (macroeconomic data is not available for periods shorter than the month), but also the macro time series involve mixed effects: it is not just the distinction between noise and nonlinearities that is in order, but also the eventual source of nonlinearity.

Little or no evidence for chaos has found in macroeconomic time series. Investigators have found substantial evidence for nonlinearity but relatively weak evidence for chaos per se. That is due to the small samples and high noise levels for most macroeconomic series; they are usually aggregated time series coming from a system whose dynamics and measurement probes may be changing over time. In contrast to the laboratory experiments where a large amount of data points can easily be obtained, most economic time series consists of monthly, quarterly, or annual data, with the exception of some financial data with daily or weekly time series.

In fact the analysis of financial time series has led to results which are, as a whole, more reliable than those of macroeconomic series. Financial time-series are a good candidate for analyzing chaotic behaviour. The reason is to be available in large quantities and for much disaggregated time intervals.

The failure to find convincing evidence for chaos in economic time series redirected the interest to additional tests that work with small data sets, and are robust against noise . This goal seems to be reached by topological tools, like recurrence analysis characterised by the study of the organisation of the strange attractor. They exploits an essential property of a chaotic system, the recurrence

${ }^{4}$ Details of which may be found in [52] and subsequent generalisation in [53]. 
property, i.e. the tendency of the time series to nearly, although never exactly, repeat itself over time.

The topological method has been successfully applied in the sciences to detect chaos in experimental data [5659] and it has been demonstrated to work well on relatively small data sets and to be robust against noise [60].

The tools based on topological invariant testing procedure (close return test and recurrence plot) compared to the existing metric class of testing procedures including correlation dimension, the BBS test and Lyapunov exponent are better suited to testing for chaos in financial and economic time series and to prove the existence of chaos in particular in macroeconomic time series [56,57].

In the literature the tools based on the topological approach are Close Return Test and Recurrence Plot.

\section{Conclusions}

The assumptions of mainstream economics are totally changing. Not more the Olympic rationality but processes in which the interacting economic agents adapt itself in reaction to environment and, by innovating, contribute to its change.

In this ever changing environment, it is almost impossible to prefigure the outcome of decisions with a satisfactory degree of precision and use constrained optimization models to capture the behavior of these complex adaptive systems.

Models have been built that unjustifiably claim to be scientific because they are based on the idea that the economy behaves like a rational individual, when the real economics provides a wealth of evidence showing that the rationality in question has little or nothing to do with how people behave.

Economies are complex adaptive systems, that is, composed of a large number of interacting components and of the relationships between them. "The goal of complex systems research is to explain in a multidisciplinary way how complex and adaptive behaviour can arise in systems composed of large numbers of relatively simple components, with no central control, and with complicated interactions” [61,62].

Not more aggregate reduced to the analysis of a single, representative, individual, ignoring by construction any form of heterogeneity and interaction, but the aggregate emerging from the local interactions of agents.

Aggregate phenomena, are intrinsically complex because social interaction of boundedly rational agents implies features that are not observable at the level of the individual.

Therefore, recognizing the existence of deterministic chaos in economics is important from both a theoretical and a practical point of view. From the theoretical point of view, if a system is chaotic we may construct mathematical models which would provide a deeper understan- ding of its dynamics. From the practical point of view, the discovery of chaotic behaviours makes it possible to control them.

Finding chaos in GNP series may mean that nonlinear dynamics are observable in the relation among economic aggregates, but it can also mean that some chaotic external shock (e.g. in the physical environment or in technology) disturbs the economy. In this way, the problem is not only one of finding chaos in the economy, it is also to detect if the hypothetically found chaos is generated inside of the structure of the economy. In other words, finding evidence of chaos is half of the problem, the other half consists in finding where from the chaos is coming.

Moreover chaotic series have another advantage from a policy perspective. Since routes to chaos are generally characterized by a process where fluctuations exist only for specific sets of parameter values, if authorities control some of the bifurcation parameters then they can manipulate their values in order to attain a region of fixed point stability; if the evolution of economic aggregates over time is of a stochastic nature, no parameter change would allow for a stabilizing effect.

In the field of control systems the main criticism moved to models built on these assumptions arises from the fact that they mislead a real understanding of the economic phenomenon and can induce inadequate and erroneous economic policies [63]. An incorrect policy advice based on the wrong theory produces effects that will be fundamentally different from those predicted by the theory. An alternative to performing adequate policies with different consequences from those associated with more conventional models [64] could be the use of chaotic models.

Using sensitivity for initial conditions to move from given orbits to other ones of attractors means to choose different behaviour of the systems, that is, different tradeoff of economic policy. Moreover the employment of an instrument of control in terms of resources in order to achieve a specific goal of economic policy will be smalller if compared to the use of traditional techniques of control. Applying chaotic control can be expected to produce greater efficiency that is resources, to achieve economic policy goals. We can obtain a relatively large improvement in system performance by the use of small controls. Resource saving and choosing among different trade-offs of economic policies (many orbits) could be significant motivations to use chaotic models in economic analysis.

Yet despite such limitations economists frequently talk as if deductions from general equilibrium theory are applicable to reality and to provide a credible explanation of observed economic phenomena and a guide to economic policy making

But the theory ploughed ahead ignoring its own weaknesses, despite the criticisms of many mathematicians and 
economists.

The reason of this could be resumed in words by Barnett [65] "It is my belief that the economics profession, to date, has provided no dependable empirical evidence of whether or not the economy itself produces chaos, and I do not expect to see any such results in the near future. The methodological obstacles in mathematics, numerical analysis, and statistics are formidable".

\section{Acknowledgements}

This publication has been carried out with financial support of the project CRISE-University of Salerno.

\section{REFERENCES}

[1] M. Allais, "The Economic Science of Today and Global Disequilibrium,” In: M. Baldassarri, J. McCallum and R. A. Mundell, Eds., Global Disequilibrium in the World Economy, Macmillan, Basingstoke, 1992.

[2] B. Cohen, "The Natural Sciences and the Social Sciences: Some Historical and Critical Perspectives,” Boston Studies in the Philosophy of Science, Boston, 1993.

[3] W. S. Jevons, “The Theory of Political Economy," London Journal, Vol. 57, No. 2, 1924, pp. 289-307.

[4] J. von Newman and O. Morgenstern, "Theory of Games and Economic Behavior," Princeton University Press, Princeton, 1944.

[5] P. Samuelson, "Interactions between the Multiplier Analysis and the Principle of Acceleration," Review of Economics and Statistics, Vol. 21, No. 2, 1939, pp. 75-78. doi:10.2307/1927758

[6] N. Georgescu-Roegen, "The Entropy Law and the Economic Process,” Harvard University Press, Cambridge, 1971.

[7] T. Sousa and T. Domingos, "Is Neoclassical Microeconomics Formally Valid? An Approach Based on an Analogy with Equilibrium Thermodynamics," Ecological Economics, Vol. 58, No. 1, 2006, pp. 160-169. doi:10.1016/j.ecolecon.2005.07.004

[8] R. Frisch, "Econometrics in the World Today,” In: W. A. Eltis, M. F. Scott and J. N. Wolfe, Eds., Induction, Growth and Trade: Essays in Honour of Sir Roy Harrod, Clarendon P., London, 1970.

[9] R. M. Solow, "How Did Economics Get That Way and What Way Did It Get?” Daedalus, Vol. 126, No. 1, 1997, pp. 39-58.

[10] D. Colander, "The Economics Profession, the Financial Crisis, and Method," Journal of Economic Methodology, Vol. 17, No. 4, 2011, pp. 419-427. doi:10.1080/1350178X.2010.525039

[11] H. Poincaré, "La Valeur de la Science,” Flammarion, Paris, 1905.

[12] A. Kirman, "Economic Theory and the Crisis," VOXResearch-Based Policy Analysis And Commentary from Leading Economists, London, 14 November 2009.

[13] H. Markowitz, "Portfolio Selection,” Journal of Finance,
Vol. 7, No. 1, 1972, pp. 77-91. doi:10.2307/2975974

[14] F. Black and M. Scholes, "The Pricing of Options and Corporate Liabilities,” Journal of Political Economy, Vol. 81, No. 3, 1973, pp. 637-654. doi:10.1086/260062

[15] A. Mas-Colell, M. Whinston and J. Green, "Microeconomic Theory,” Oxford University Press, Oxford, 1995.

[16] D. Colander, Ed., "Beyond Microfoundations: Post-Walrasian Macroeconomics,” Cambridge University Press, New York, 1996.

[17] J. A. Holyst and K. Urbanowicz, "Chaos Control in Economical Model by Time Delayed Feedback Method," Physica A, Vol. 287, No. 3-4, 2000, pp. 587-598. doi:10.1016/S0378-4371(00)00395-2

[18] A. Medio, “Teoria Non-Lineare del Ciclo Economico,” Il Mulino, Bologna, 1979.

[19] M. J. Stutzer, "Chaotic Dynamics and Bifurcation in a Macro Model,” Staff Report 55, Federal Reserve Bank of Minneapolis, Minneapolis, 1980.

[20] J. Benhabib and R. Day, "Rational Choice and Erratic Behaviour,” Review of Economic Studies, Vol. 48, No. 3, 1981, pp. 459-472. doi:10.2307/2297158

[21] R. H. Day, "Irregular Growth Cycles," American Economic Review, Vol. 72, No. 3, 1982, pp. 406-414.

[22] J. M. Grandmont, “On Endogenous Competitive Business Cycles,” Econometrica, Vol. 53, No. 5, 1985, pp. 9951045. doi:10.2307/1911010

[23] J. Benhabib and K. Nishimura, "The Hopf Bifurcation and the Existence and Stability of Closed Orbits in Multisector Models of Optimal Economic Growth,” Journal of Economic Theory, Vol. 21, No. 3, 1979, pp. 421-444. doi:10.1016/0022-0531(79)90050-4

[24] M. Boldrin and L. Montrucchio, "On the Indeterminacy of Capital Accumulation Paths," Journal of Economic Theory, Vol. 40, No. 1, 1986, pp. 26-29. doi:10.1016/0022-0531(86)90005-0

[25] R. A. Dana and P. Malgrange, "The Dynamics of a Discrete Version of a Growth Cycle Model,” In: J. P. Ancot, Ed., Analyzing the Structure of Econometric Models, Martinus Nijhoff Publishers, Hague, 1984 doi:10.1007/978-94-009-6098-5_7

[26] R. Deneckere and S. Pelikan, “Competitive Chaos,” Journal of Economic Theory, Vol. 30, 1986, pp. 13-25. doi:10.1016/0022-0531(86)90004-9

[27] C. H. Hommes, "Chaotic Dynamics in Economics Models. Some Single Case Studies,” Wolthers-Nordhoff, Gronigen, 1991

[28] V. Bala, M. Majumdar and T. Mitra, "A Note on Controlling a Chaotic Tatonnement," Journal of Economic Behavior \& Organization, Vol. 33, No. 3-4, 1998, pp. 411420. doi:10.1016/S0167-2681(97)00066-8

[29] Z. T. Mitra, "A Sufficient Condition for Topological Chaos with an Application to a Model of Endogenous Growth,” Journal of Economic Theory, Vol. 96, No. 1-2, 2001, pp. 133-152. doi:10.1006/jeth.2000.2738

[30] J. M Grandmont, "Stabilizing Competitive Business Cycle,” Journal of Economic Theory, Vol. 40, No. 1, 1986, pp. 57-76. doi:10.1016/0022-0531(86)90007-4 
[31] J. M. Grandmont and G. Laroque, "Stability of Cycles and Expectations," Journal of Economic Theory, Vol. 40, No. 1, 1986, pp. 138-151. doi:10.1016/0022-0531(86)90012-8

[32] R. Farmer, "Deficits and Cycles," Journal of Economic Theory, Vol. 40, No. 1, 1986, pp. 77-88. doi:10.1016/0022-0531(86)90008-6

[33] P. Reichlin, "Equilibrium Cycles and Stabilization Policies in an Overlapping Generations Economy with Production," Journal of Economic Theory, Vol. 40, No. 1, 1986, pp. 89-102. doi:10.1016/0022-0531(86)90009-8

[34] C. Chiarella, "The Cobweb Model: Its Instability and the Onset of Chaos,” Economic Modelling, Vol. 5, No. 4, 1988, pp. 377-384. doi:10.1016/0264-9993(88)90010-7

[35] T. Puu, “Chaos in Duopoly Pricing," Chaos, Solitons \& Fractals, Vol. 1, No. 6, 1991, pp. 573-581. doi:10.1016/0960-0779(91)90045-B

[36] E. Ott, C. Grebogi and J. A. Yorke, “Controlling Chaos,” Physical Review Letters, Vol. 64, No. 11, 1990, pp. 11961199. doi:10.1103/PhysRevLett.64.1196

[37] M. Faggini, “Analysis of Economic Fluctuations: A Contributions from Chaos Theory," In: M. Sibillo and C. Perna, Eds., Mathematical and Statistical Methods for Insurance and Finance, Springer, Berlin, 2008. doi:10.1007/978-88-470-0704-8_14

[38] M. Faggini, "Chaotic Systems and New Perspectives for Economics Methodology. A Review from Literature,” In: K. A. Dennard and G. Morcol, Eds., Complexity and Policy Analysis: Tools and Concepts for Designing Robust Policies in Complex World, ISCE Publishing, Goodyear, 2008.

[39] G. Orlando, "Routes to Chaos in Macroeconomic Theory,” Journal of Economic Studies, Vol. 33, No. 6, 2006, pp. 437-468. doi:10.1108/01443580610710406

[40] J. A. Holyst, "How to Control a Chaotic Economy," Journal of Evolutionary Economics, Vol. 6, No. 1, 1996, pp. 31-42. doi:10.1007/BF01202371

[41] L. Kaas, "Stabilizing Chaos in a Dynamic Macroeconomic Model," Journal of Economic Behavior and Organisation, Vol. 33, No. 3-4, 1998, pp. 313-332. doi:10.1016/S0167-2681(97)00061-9

[42] M. Kopel, "Improving the Performance of an Economic System: Controlling Chaos," Journal of Evolutionary Economics, Vol. 7, No. 3, 1997, pp. 269-289. doi:10.1007/s001910050044

[43] D. L. Xu , Z. G. Li, S. R. Bishop and U. Galvanetto, "Estimation of Periodic-Like Motions of Chaotic Evolutions Using Detected Unstable Periodic Patterns," Pattern Recognition Letters, Vol. 23, No. 1-3, 2002, pp. 245-252. doi:10.1016/S0167-8655(01)00100-3

[44] W. A. Barnett and P. Chen, "Deterministic Chaotic and Fractal Attractors as Tools for Nonparametric Dynamical Econometric Inference: With an Applications to Divisia Monetary Aggregates,” Mathematical Computational Modelling, Vol. 10, 1988, pp. 275-296.

[45] W. A. Barnett and P. Chen, "The Aggregation Theoretic Monetary Aggregates Are Chaotic and Have Strange Attractors: An Econometric Application of Mathematical of
Chaos,” In: W. A. Barnett, E. Berndt and H. White, Eds., Dynamic Econometric Modeling, Cambridge University Press, Cambridge, 1988. doi:10.1017/CBO9780511664342.012

[46] W. Brock and C. Sayers, "Is the Business Cycle Characterized by Deterministic Chaos?” Journal of Monetary Economics, Vol. 22, No. 1, 1988, pp. 71-70. doi:10.1016/0304-3932(88)90170-5

[47] J. B. Ramsey, C. L. Sayers and P. Rothman, “The Statistical Properties of Dimension Calculations using Small Data Sets: Some Economic Applications,” In: J. Benhabib, Ed., Cycles and Chaos in Economic Equilibrium, Princeton University Press, Princeton, 1991.

[48] G. P. DeCoster and D. W. Mitchell, "Nonlinear Monetary Dynamics," Journal of Business \& Economic Statistics, Vol. 9, No. 4, 1991, pp. 455-461. doi:10.2307/1391245

[49] G. P. DeCoster and D. W. Mitchell, "Reply,” Journal of Business \& Economic Statistics, Vol. 12, No. 1, 1994, pp. 136-137. doi:10.2307/1391931

[50] P. Grassberger and I. Procaccia, "Measuring the Strangeness of Strange Attractors," Physica D, Vol. 9, No. 1-2, 1983, pp. 189-208. doi:10.1016/0167-2789(83)90298-1

[51] D. Ruelle, “Chance and Chaos,” Princeton University Press, Princeton, 1991.

[52] W. D. Dechert, "Chaos Theory in Economics: Methods, Models and Evidence,” Edward Elgar Publishing, Cheltenham, 1996.

[53] M. D. McKenzie, "Chaotic Behaviour in National Stock Market Indices. New Evidence from the Close Returns Test,” Global Finance Journal, Vol. 12, No. 1, 2001, pp. 35-53. doi:10.1016/S1044-0283(01)00024-2

[54] W. A. Brock, W. D. Dechert and J. Scheinkman, “A Test for Independence Based on the Correlation Dimension," Econometric Reviews, Vol. 15, No. 3, 1996, pp. 197-235. doi:10.1080/07474939608800353

[55] B. LeBaron, "Chaos and Nonlinear Forecast Ability in Economics and Finance,” Department of Economics, University of Wisconsin, Madison, 1994.

[56] M. Faggini, "Visual Recurrence Analysis: An Application to Economic Time Series,” In: M. Salzano and D. Colander, Eds., Complexity Hints for Economic Policy, Springer, Berlin, 2007. doi:10.1007/978-88-470-0534-1_4

[57] M. Faggini, "Chaos Detection in Economics. Metric versus Topological Tools,” MPRA Paper No. 30928, Munich Personal RePEc Archive, Munich, 2011.

[58] G. B. Mindlin, et al., "Classification of Strange Attractors by Integers,” Physical Review Letters, Vol. 64, No. 20, 1990, pp. 2350-2353. doi:10.1103/PhysRevLett.64.2350

[59] G. B. Mindlin and R. Gilmore, "Topological Analysis and Synthesis on Chaotic Time Series,” Physica D, Vol. 58, No. 1-4, 1992, pp. 229-242. doi:10.1016/0167-2789(92)90111-Y

[60] C. G. Gilmore, “A New Test for Chaos,” Journal of Economic Behaviour Organisations, Vol. 22, No. 2, 1993, pp. 209-237. doi:10.1016/0167-2681(93)90064-V

[61] M. Mitchell, “A Complex-Systems Perspective on the 'Computation vs Dynamics' Debate in Cognitive Sci- 
ence," 20th annual conference of the Cognitive Science Society, Madison, 1-4 August 1998.

[62] J. P. Crutchfield, "Is Anything Ever New? Considering Emergence,” In: G. Cowan, D. Pines and D. Meltzer, Eds., Complexity: Metaphors, Models, and Reality. AddisonWesley, Boston, 1994, pp. 515-537.

[63] J. B. Bullard and A Butler, "Nonlinearity and Chaos in Economic Models: Implications for Policy Decisions," Economic Journal, Vol. 103, No. 419, 1993, pp. 849-867. doi: $10.2307 / 2234705$

[64] A. W. Huebler and B. B. Plapp, "Nonlinear Resonances and Suppression of Chaos in the rf-Biased Josephson Junction,” Physical Review Letter, Vol. 65, No. 18, 1990, pp. 2302-2305. doi:10.1103/PhysRevLett.65.2302

[65] W. A. Barnett, "Comment on 'Chaotic Monetary Dynamics with Confidence," Journal of Macroeconomics, Vol. 28, No. 1, 2006, pp. 253-255. doi:10.1016/j.jmacro.2005.10.018 